TITLE:

\title{
Short- and Long-Term
}

Observations of Fracture Permeability in Granite by FlowThrough Tests and Comparative Observation by X-Ray CT

\section{$\operatorname{AUTHOR}(S)$ :}

Song, Chenlu; Nakashima, Shinichiro; Kido, Ryunosuke; Yasuhara, Hideaki; Kishida, Kiyoshi

\section{CITATION:}

Song, Chenlu ... [et al]. Short- and Long-Term Observations of Fracture Permeability in Granite by Flow-Through Tests and Comparative Observation by X-Ray CT. International Journal of Geomechanics 2021, 21(9): 04021151.

\section{ISSUE DATE:}

2021-09

URL:

http://hdl.handle.net/2433/264255

\section{RIGHT:}

This material may be downloaded for personal use only. Any other use requires prior permission of the American Society of Civil Engineers. This material may be found at https://ascelibrary.org/doi/10.1061/(ASCE)GM.1943-

5622.0002114.; This is not the published version. Please cite only the published version. この論文は出版社版でありませ ん。引用の際には出版社版をご確認ざ利用ください。 
1 Short- and long-term observations of fracture permeability in granite by flow-through

2 tests and a comparative observation by X-ray CT

3 Chenlu Song ${ }^{1}$, Shinchiro Nakashima ${ }^{2}$, Ryunosuke Kido ${ }^{3}$, Hideaki Yasuhara ${ }^{4}$ and Kiyoshi

4 Kishida $^{1}$

5

$6 \quad{ }^{1,5}$ Department of Urban Management, Kyoto University, Kyoto, 615-8540, JAPAN.

$7 \quad{ }^{2}$ Department of Civil and Environmental Engineering, Yamaguchi University, Yamaguchi, 755-

$8 \quad 8611$ JAPAN

$9{ }^{3}$ Department of Civil and Earth Resources Engineering, Kyoto University, Kyoto, 615-8540, 10 JAPAN.

${ }^{4}$ Department of Civil and Environmental Engineering, Ehime University, Matsuyama, 7908577, JAPAN. 


\section{Abstract}

To grasp the fracture contact-area variation is a kernel on understanding the permeability evolution of the fractured rocks. However, there is a lack of studies focusing on measuring the long-term fracture contact-area variation under different conditions. In this study, a series of short- and long-term permeability tests under coupled conditions are performed to check the permeability performance. Permeability is sensitive to confining pressures and shows temperature dependence in the short-term tests, and it has the irreversible change and timedependence in the long-term tests. In order to verify the permeability evolution, by assembling a triaxial cell with heating capability, a microfocus X-ray CT is developed to observe the internal fracture structure change under the same conditions with the long-term permeability tests. The fracture aperture and the fracture contact-area ratio are calculated by CT image analysis technique. The estimated aperture decreases with increase of the confining pressure, and it decreases with time under the constant confining pressure. Moreover, the hydraulic aperture calculated from the CT observation is qualitatively consistent with that measured in the long-term permeability tests. It is clarified that the fracture contact-area increase with time under the constant confining pressure corresponds to the permeability decrease in the long-term.

Keywords: Permeability, short- and long-term, X-ray CT observation, contact-area ratio and aperture distribution 


\section{Introduction}

The flow behavior in the deep subsurface has been given great attention in recent years.

The coupled thermal-hydraulic-mechanical-chemical (THMC) processes exert a significant effect on the subsurface fluid flow in geological systems (Ghassemi et al., 2007; Taron et al., 2010; Frdric et al., 2017). Especially during the geological disposal of high-level radioactive waste, the stability of the disposal system may be affected by the long-term water flow around the rock fractures (Rutqvist et al., 2002; Yasuhara et al., 2015; Tsang et al., 2012;). Moreover, the coupled THMC processes might change the underground water flow paths, and then the transport of radionuclides will be promoted. Under the coupled interaction, the mechanical creep (stress corrosion) (Yasuhara et al., 2006; Xu et al., 2016) and the geochemical response (variation in mineral composition) (Polak and Beeler, 2004; Yasuhara et al., 2006, 2011; Elkhoury et al., 2013) altering the fracture surface roughness and transforming the long-term permeability evolution are discussed.

Several numerical works focusing on the prediction of the variation in permeability under the coupled THMC processes have been proposed (Taron et al., 2010; Zhang et al., 2013; Wang, 2017). However, not many laboratory works have addressed the long-term fluid flow behavior within the rock fractures or the changing of the fracture contact-area under the THMC coupled processes (Li et al., 2008; Yasuhara et al., 2015; Xu et al., 2016). Polak et al. (2003), Yasuhara et al. (2015), and Farough et al. (2016) conducted several long-term experiments, and the results showed that the fracture surface roughness was altered, and the aperture decreased at higher temperatures, which resulted in the permeability reduction. From the experimental studies, it is seen that under the coupled processes, the fracture contact-area should be evolved with time. 
60

61

Subsequently, the fluid flowing through the fracture would be disturbed by the evolved fracture contact-area (Zimmerman et al., 1996; Li et al., 2008; Kishida et al., 2013). However, the evolution of the fracture contact-area has not been well investigated in the previous studies, because it is not simple to grasp the fracture contact-area immediately through the laboratory tests.

From the previous works, it is noted that the temporal fracture structure change needs to be further investigated. X-ray computed tomography (CT) (Van et al., 2001; Yao et al., 2009; Ketcham et al., 2010) is an effective technique which can detecting the internal structure non-destructively and three-dimensionally (Robert et al., 1993; Fan et al., 2018). Therefore, it is possible to grasp various rock samples with fractures or cracks under the flow test. (Stephanie et al., 2001; Karpyn et al., 2007, 2009; Dustin et al., 2017; Lu and Kumaria, 2018). The measured data is used to reconstruct a 3D view for illustrating the fracture heterogeneous distribution (Keller, 1998; Kawakata et al., 1999; Mazumder et al., 2006; Yao et al., 2009; Richard et al., 2010; Hamed et al., 2016). Moreover, some researchers try to use microfocus X-ray CT to observe the fracture changing under varying conditions (Polak et al., 2003; Yasuhara et al., 2015; Okamoto et al., 2017). Polak et al., (2003) studied the fracture change under different temperatures $\left(20,80\right.$ and $\left.120^{\circ} \mathrm{C}\right)$, the mass removed from the fracture contact-area and the decrease in hydraulic aperture were investigated. Okamoto et al., (2017) showed a comparison of the CT scanning images between a sample at room temperature and at the temperature of $350^{\circ} \mathrm{C}$. The quartz distribution illustrated that the flow rate was changed due to the mineral dissolution or the precipitation generated at $350^{\circ} \mathrm{C}$. Yasuhara et al., (2015) conducted a series of permeability tests with several types of rock samples. Pore structures were observed through X-ray CT with a comparison between the pre- and post-experiment. The 
changing pore structures might support the variation in permeability. (Caulk et al., 2016; Kamali-Asl et al., 2018) found that the aperture would close at higher levels of confining stress. The higher levels of confining stress resulted in a change in the sensitivity of the variable fracture contact-area ratio.

However, previous laboratory studies have not directly observed the temporal change of the fracture contact-area under the coupled conditions. There is a lack of interpretation of the relationship between the long-term permeability changing and the fracture contact-area variation through laboratory works. Therefore, to further understand the long-term permeability evolution under coupled processes, this study focuses on several permeability tests under different conditions, especially for the variation in permeability over the long-term under a constant confining pressure. An X-ray CT observation as well as the long-term permeability tests are conducted to obtain the changes of the aperture distribution and the fracture contactarea. Finally, several indexes, such as the fracture contact-area ratio, the aperture distribution and a comparison of the hydraulic aperture change, are discussed.

\section{Sample materials and experimental procedures}

\subsection{Fracture generation and morphology}

Figure 1 presents the geometry of the samples used in this study. Two cylindrical granite samples, Sample \#1 and Sample \#2, with a size of $49.3 \times 101.2 \mathrm{~mm}$ and $15.2 \times 33.3 \mathrm{~mm}$, respectively, are employed. Samples \#1 and \#2 are used for the permeability tests and the Xray CT observation, respectively. Before the experiments, both samples are split by the Brazilian tensile testing method to create a single fracture along the cylinder axis (Fairhurst, 1964). The mechanical properties of the granite samples are listed in Table 1. 
Table 1 Mechanical properties of granite sample

108

\begin{tabular}{ccccc}
\hline Sample & $\begin{array}{c}\text { Uniaxial } \\
\text { compression strength } \\
(\mathrm{MPa})\end{array}$ & $\begin{array}{c}\text { Young's modulus } \\
(\mathrm{GPa})\end{array}$ & Poisson's ratio & $\begin{array}{c}\text { Tensile strength } \\
(\mathrm{MPa})\end{array}$ \\
Granite & 140.3 & 55.4 & 0.2 & 6.2 \\
\hline
\end{tabular}

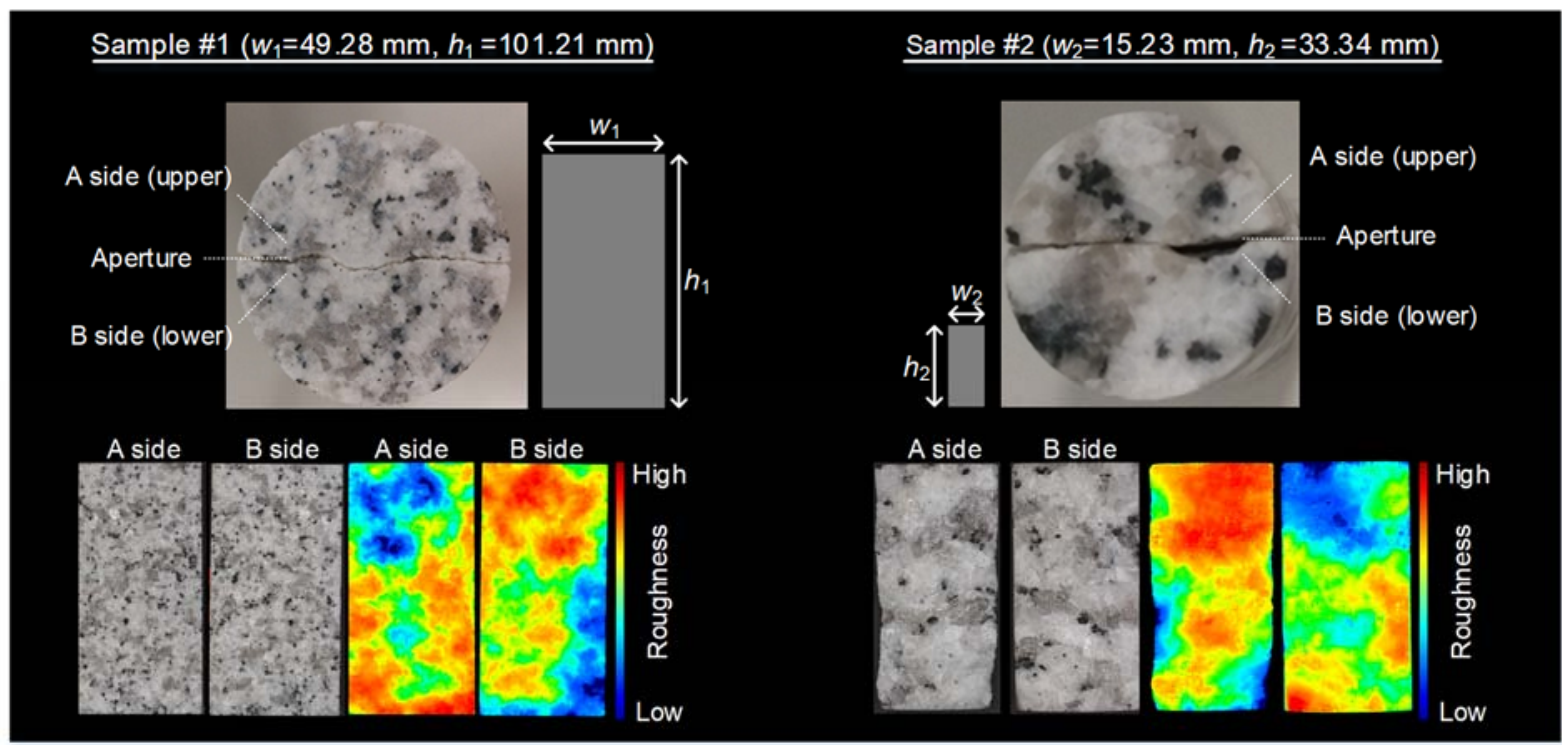

Fig. 1 Sample experiments and fracture surfaces measured by laser profilometer

In this study, the initial granite surface roughness before the experiments is evaluated by the JRC values. An optical profilometer is employed, using the pattern projection method (VR3200, Keyence Corporation in Japan), to grasp the morphology of the fracture surfaces. The profilometer is capable of measuring the surface roughness in a grid pattern through non-contact.

118 The grid size of the elevation measurement is $25 \mu \mathrm{m}$ and the measurement resolution of the

119 profilometer is $0.1 \mu \mathrm{m}$. The color contour maps in Fig. 1 illustrate the elevations of the surface roughness.

To clarify the variation in fracture surface roughness, it is necessary to grasp the surface 
123 Coefficient) profiles is selected as the comparison index. Typically, the JRC value ranges from

1240 to 20 in the shear behavior of the rock joints (Barton et al., 1977,1997). The JRC values can

125 be calculated with the dimensionless parameter $Z_{2}$ (Tse ta al., 1979), which has been widely

126 discussed and is defined as follows (Zhang and Dimadis, 2014; Yin et al., 2017; Yong et al., 2018):

$$
Z_{2}=\left[\frac{1}{M-1} \sum_{i=1}^{M-1}\left(\frac{\Delta y}{\Delta x}\right)_{1}^{2}\right]^{\frac{1}{2}}
$$

where $\Delta x$ is the sampling interval, $\Delta y$ is the difference between two adjacent points and $M$ is

130 the number of sampling points along the length of the fracture surface. Subsequently, the JRC values can be evaluated by

$$
J R C=60.32 Z_{2}-4.51(\Delta x=0.25 \mathrm{~mm})
$$

Table 2 lists the $Z_{2}$ and JRC values for both surfaces of Samples \#1 and \#2. The JRC values for the two samples are around 20 . The initial values are used to evaluate the difference in surface roughness between the pre- and post-experiment.

Table 2 Comparison of Z2 and JRC values with profilometer equipment (VR-3200)

\begin{tabular}{lcc}
\hline & A side & $\left(\mathrm{JRC}=60.32 * \mathrm{Z}_{2}-4.51\right) 0.25 \mathrm{~mm}$ \\
Sample \#1 & 19.9 & B side \\
Sample \#2 & 22.8 & 20.2 \\
& & 20.4 \\
\hline
\end{tabular}

\subsection{Transient pulse method}

To investigate the permeability evolution under various conditions, the transient pulse pressures between the upstream and downstream in Eq. (3) are different. The tank is located 
injected water, then the permeability is measured from the pressure gradient generated between the two ends of the sample and the lapse of time. With the passage of time, the difference in pressure will reach a new equilibrium, given as:

$$
\begin{aligned}
& P_{d}=\frac{V_{u} P_{u}^{0}+V_{d} P_{d}^{0}}{V_{u}+V_{d}}-\frac{V_{u}}{V_{u}+V_{d}}\left(P_{u}^{0}-P_{d}^{0}\right) \exp \left(-\frac{k}{\beta \mu} \frac{A}{L} \frac{V_{u}+V_{d}}{V_{u} V_{d}} t\right) \\
& P_{u}=\frac{V_{u} P_{u}^{0}+V_{d} P_{d}^{0}}{V_{u}+V_{d}}-\frac{V_{d}}{V_{u}+V_{d}}\left(P_{u}^{0}-P_{d}^{0}\right) \exp \left(-\frac{k}{\beta \mu} \frac{A}{L} \frac{V_{u}+V_{d}}{V_{u} V_{d}} t\right)
\end{aligned}
$$

Where $P_{u}$ and $P_{d}$ are the upstream and downstream pressure, respectively, and $V_{u}$ and $V_{d}$ are the volume of two reservoirs, i.e., the volume of each reservoir is equal to $0.001 \mathrm{~m}^{3}$ in this work. $A$ and $L$ are the cross-section and the length of the sample, respectively, $\mu$ is the viscosity of the fluid and $\beta$ is the fluid compressibility. $\mu$ and $\beta$ are temperature-dependent (Walsh, 1981). Then the coefficient of permeability can be evaluated from the following equations:

$$
\begin{gathered}
\ln \left(\left(P_{u}-P_{d}\right) / 2\right)=\ln \left(\frac{V_{d}}{V_{u}+V_{d}}\left(P_{u}^{0}-P_{d}^{0}\right)\right)-\frac{k}{\beta \mu} \frac{A}{L} \frac{V_{u}+V_{d}}{V_{u} V_{d}} t \\
\alpha=-\frac{k}{\beta \mu} \frac{A}{L} \frac{V_{u}+V_{d}}{V_{u} V_{d}}
\end{gathered}
$$

In Eq. (5), A represents the cross-sectional area of the sample. In this study, however, the fluid only flows through the fracture aperture. Therefore, cross-section $A$ should be changed to $A=$ $b \times W$, where $W$ is the width of the sample and $b$ is the hydraulic aperture. Consequently, based on the cubic law, Eq. (5) is rewritten as follows:

$$
\alpha=-\frac{b^{3}}{12 \beta \mu} \frac{W}{L} \frac{V_{u}+V_{d}}{V_{u} V_{d}}
$$

Figure 2 shows a schematic illustration of the test apparatus. The granite sample (Sample \#1) is installed in a triaxial cell. The maximum pressure and temperature that can be prescribed are 20.0 MPa and $200^{\circ} \mathrm{C}$, respectively. The sample is sealed with a heat-shrinkable tube and fixed to pedestals inside the vessel. A thermocouple is installed to measure the temperature close to the sample. Two water storage tanks supply water that passes through Sample \#1. 
Differential pore water pressure gauges are used to measure the difference in pressure between

(3)

(2)

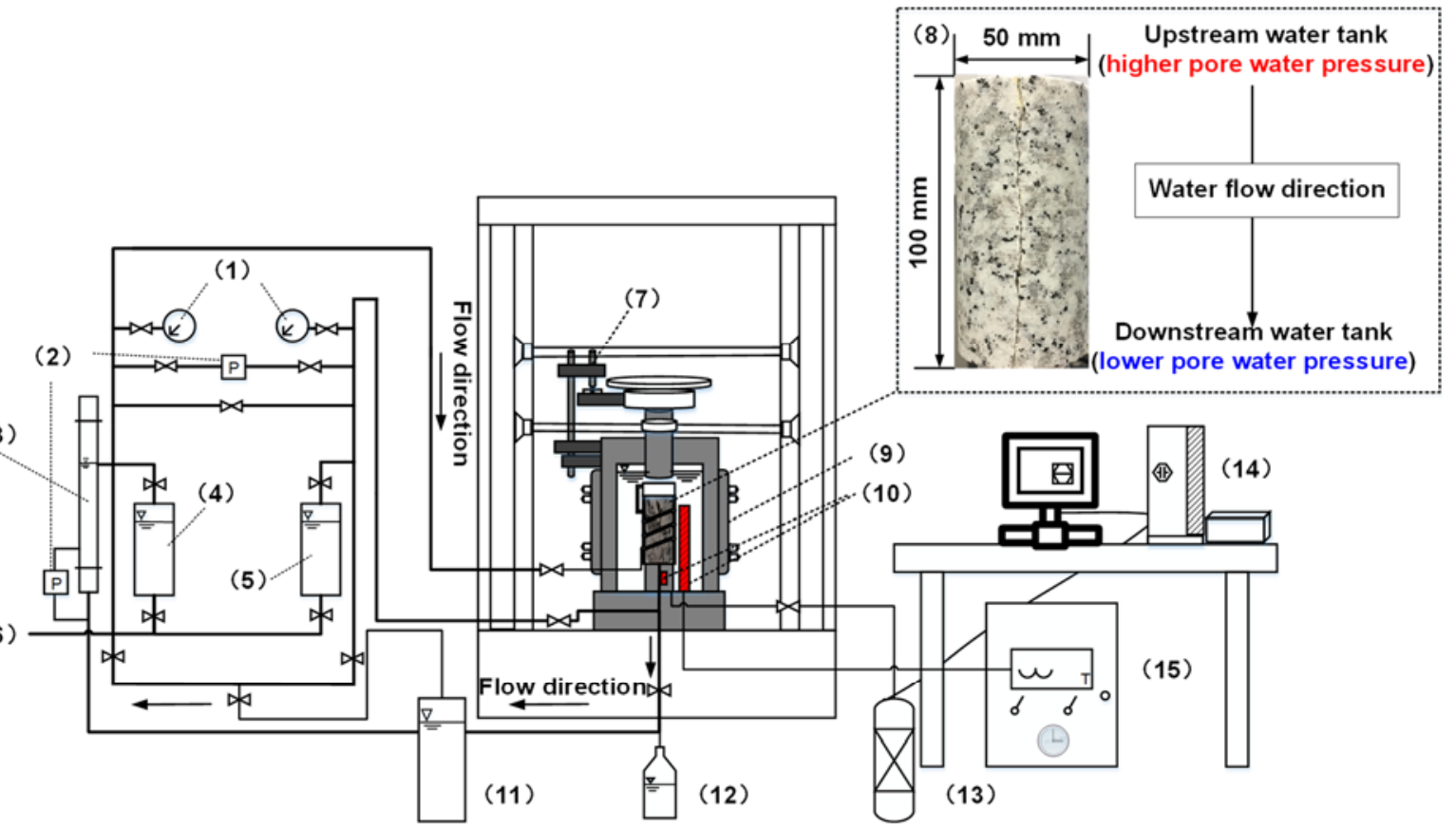

(1) Pore water pressure gauge

(2) Differential pressure gauge

(5) Downstream water tank

(9) Band heater

(13) Confining pressure

(3) Double tube Burette

(6) Pressure pump

(10) Heating system

(14) Apparatus sensor

(4) Upstream water tank

(7) LVDT

(11) Water tank

(15)Temperature gauge

(12) Extracted water from internal fracture

Fig. 2 Triaxial apparatus and Sample \#1 installed in internal cell. The upstream and downstream pore water pressures are prescribed to the top and bottom of Sample \#1, respectively

\subsection{Experimental procedure of the permeability tests (Sample \#1)}

Figure 3 shows the experimental procedure of permeability tests. A series of permeability

tests is conducted over both short- and long terms to observe the temporal changes in 
181

182 pressure difference during the elapsed time (600 seconds).

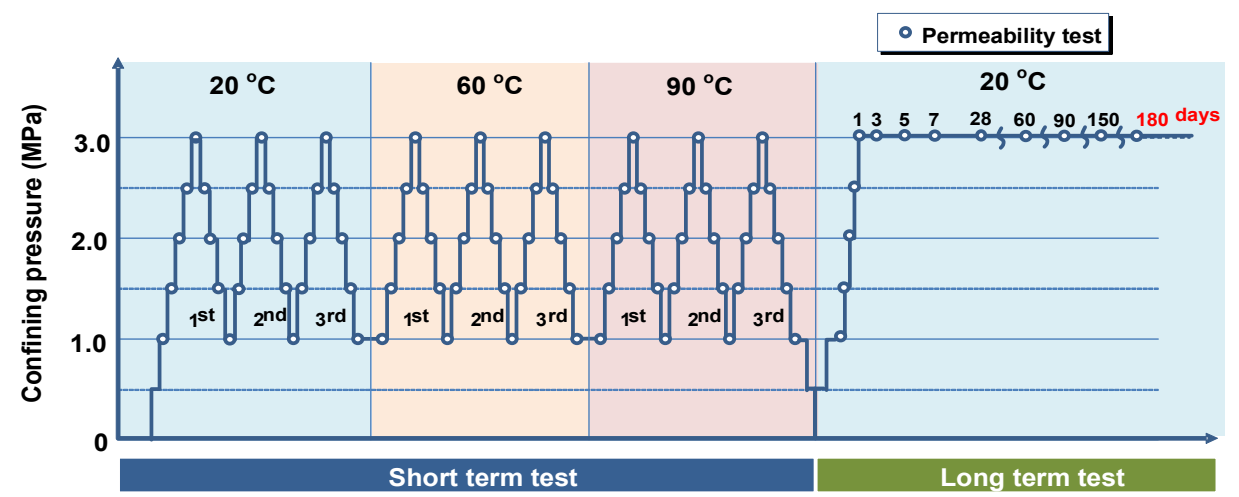

195

increments of $0.5 \mathrm{MPa}$ from 1.0 to $3.0 \mathrm{MPa}$. The permeability tests are performed simultaneously at each confining pressure.

After the short-term tests, the temperature is decreased to $20^{\circ} \mathrm{C}$. Then the long-term test is conducted under the confining pressure of $1.0 \mathrm{MPa}$ and the temperature of $20{ }^{\circ} \mathrm{C}$. The confining pressure is increased from 1.0 to $3.0 \mathrm{MPa}$ again and then keeps constant at $3.0 \mathrm{MPa}$ for 180 days. During this process, the permeability is measured at the prescribed time intervals, as shown in Fig. 3. Simultaneously, the effluent is obtained from the internal fracture, to measure the element concentrations after each permeability test. The differential pore water pressures, fluid viscosity, and fluid compressibility are listed in Table 3. The permeability values are measured under various confining pressure conditions during the loading-tounloading processes. Fig.4 shows an example of the permeability tests. A difference in pressure between the upper and lower ends of the granite Sample \#1 is produced with a slight change in the pore water pressures. Then, the permeability can be measured by the temporal change in the

Fig. 3 Experimental procedure for short- and long-term permeability tests 


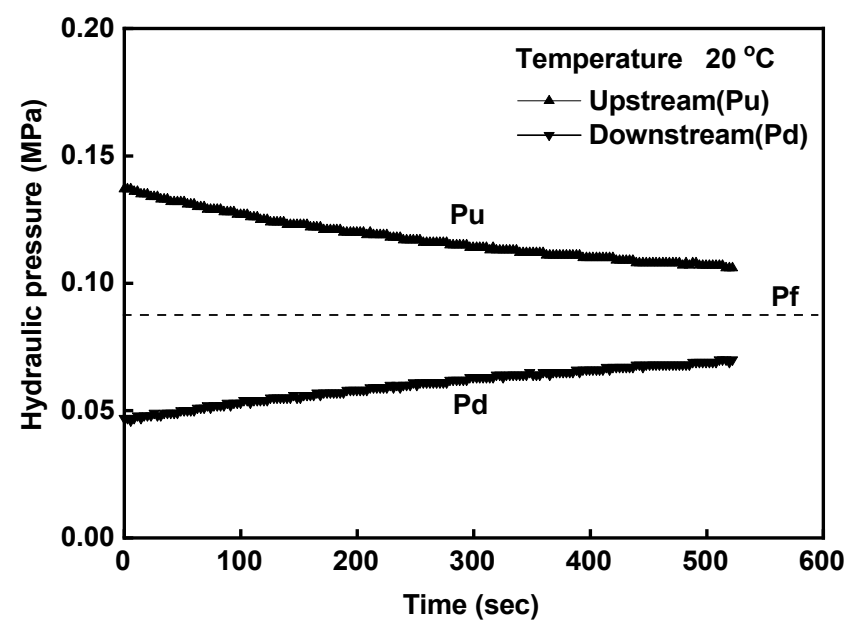

\subsection{Non-destructive observation of fracture with microfocus X-ray CT (Sample \#2)} the cell as transparent to the X-ray as possible in order to avoid the X-ray attenuation by the steel (Otani et al., 2002). With a heater installed in the cell, the maximum confining pressure and temperature can be applied up to $3 \mathrm{MPa}$ and $120^{\circ} \mathrm{C}$, respectively. The X-ray CT equipment is KYOTO-GEO $\mu$ XCT (TOSCANER-32250 $\mu \mathrm{hdk}$ ) (Kido et al., 2020). The minimum focus size is $4 \mu \mathrm{m}$ and the resolution performance is $5 \mu \mathrm{m}$.

Figure 6 shows the CT slices scanned by the X-ray CT. A CT slice is composed of a number of voxels which include CT values determined based on the amount of the X-ray

212 attenuation, depending on the material density. In the CT slice, white and black portions the sample. 


\begin{tabular}{lccccc}
\hline Confining pressure $(\mathrm{MPa})$ & 1.0 & 1.5 & 2.0 & 2.5 & 3.0 \\
Pressure at upstream tank (MPa) & 0.200 & 0.250 & 0.300 & 0.350 & 0.400 \\
Pressure at downstream tank (MPa) & 0.150 & 0.175 & 0.200 & 0.225 & 0.250 \\
Fluid viscosity $\left(10^{-10} \mathrm{Pas}\right)$ & $1.0017\left(\mathrm{~T}=20^{\circ} \mathrm{C}\right)$ & $0.467\left(\mathrm{~T}=60{ }^{\circ} \mathrm{C}\right)$ & $0.0328\left(\mathrm{~T}=90^{\circ} \mathrm{C}\right)$ \\
Compressibility $\left(10^{-3} \mathrm{~Pa}\right)$ & $4.5883\left(\mathrm{~T}=20^{\circ} \mathrm{C}\right)$ & $4.3\left(\mathrm{~T}=60^{\circ} \mathrm{C}\right)$ & $4.6\left(\mathrm{~T}=90^{\circ} \mathrm{C}\right)$ \\
\hline
\end{tabular}
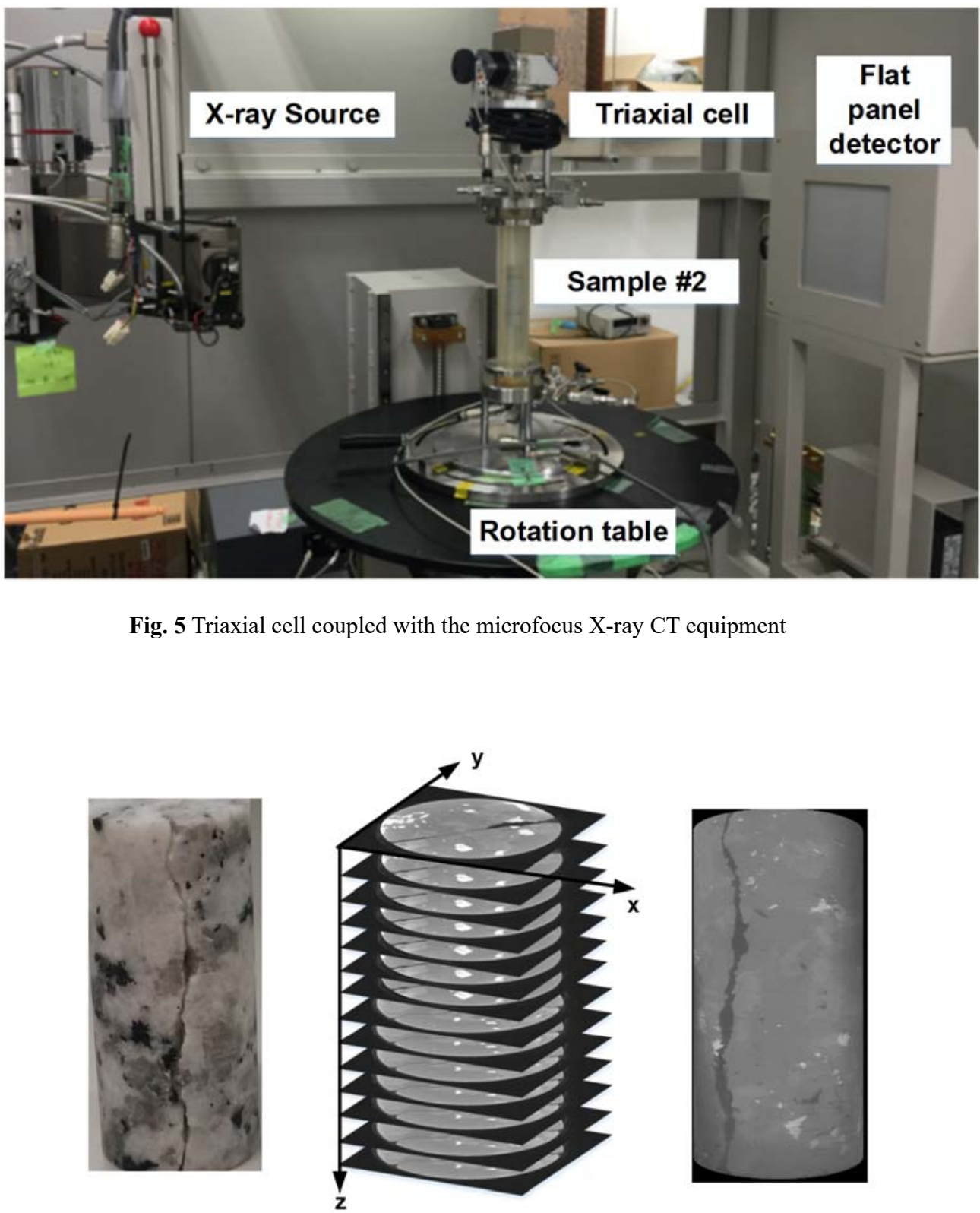

\section{Sample \#2}

Scan \& reconstruction

\section{Cumulating}

\section{D CT volume} images

Fig. 6 3D CT volume of Sample \#2 
The scanning procedure for Sample \#2 is as follows. Firstly, the initial fracture aperture is in the triaxial cell under the water-saturated condition. The confining pressure is increased up to 3.0 $\mathrm{MPa}$ and the fracture aperture is scanned. These two scans are performed in one day. Subsequently, the confining pressure is kept constant at 3.0 MPa, and CT scans are performed at 14 th, 30th, 60th, 90th, 120th, 150th and 180th days, corresponding to the same procedure with the permeability test of Sample \#1. One CT slice comprises 1024 voxels in each $x$ - and $y$ direction as shown in Fig. 6. At $0 \mathrm{MPa}$, the voxel size is $15.1 \mu \mathrm{m}, 15.1 \mu \mathrm{m}$ and $17.0 \mu \mathrm{m}$ in $x^{-}$, $y$ - and z-directions. At 3.0 MPa, the voxel size is $18.4 \mu \mathrm{m}, 18.4 \mu \mathrm{m}$ and $21.0 \mu \mathrm{m}$, respectively.

\subsection{Methodologies of CT image analysis}

\subsubsection{Segmentation}

In order to detect the fracture aperture position in the CT volume scanning Sample \#2, the segmentation of the CT images is required. As mentioned above, a CT slice is an assembly of discrete voxels including representative $\mathrm{CT}$ values for each material and thus, the segmentation can be performed based on the CT values. In the present study, the rock phase and the void phase in the CT images are distinguished from each other using a region growing method (Rosenfeld et al., 1982), which is implemented with the 3D image analysis software VGstudioMax3.1 (Volume Graphics GmbH) (Higo et al., 2014). This method examines the CT values of the neighboring voxels of initial seed voxels and determines whether the voxel neighbors should be added into the region of the seed groups. The regions are extended from the seed voxels to adjacent voxels depending on a region membership criterion, i.e., tolerance. 
and CT value), a tolerance selection (range in CT values), and voxel connectivity for

248 examination.

Figure 7 shows the outline of the image processing in this study. The procedure of the segmentation using the region growing method is as follows:

1) Assuming that a histogram of $\mathrm{CT}$ values for a homogeneous material follows a normal distribution, a mean CT value of the rock phase, $\mu_{\rho}$, is obtained by analyzing the CT values using the VGstudioMax3.1. In this study, the mean rock CT value of 151 is chosen as the initial seed of the rock phase.

2) Similarly, the mean CT value of the void phase, $\mu_{\varpi}$, of 48 is obtained. A threshold between the rock phase and the void phase is an intersection of the CT value histogram (see in Fig. 7(a)). In this study, the threshold value is 82 .

3) The tolerance of the rock phase, $T$, is the difference between the mean CT value of the rock phase and the threshold determined in the above step, i.e., the tolerance is 69. Adjacent growing is a 26-connected neighborhood in 3-dimensional, which ensures the continuity of adjacent voxels to the initial seed voxel in $x-, y$ - and $z$-directions (see Fig. 7(b)).

4) This process is iterated on until all of the neighboring voxels of the rock phase are assimilated and no further significant change is found. The remaining voxels after the iterative process of the region growing for the rock phase are regarded as the void phase, a segmentation CT image for the rock and void phase is depicted in Fig. 7(c). 


\subsubsection{Detection of fracture aperture and calculation of fracture contact-area}

Figure 7(d) shows the detection method of the internal aperture position from a CT segmentation image. A rectangular area, 800 voxels in $x$-direction and 360 voxels in $y$-direction is extracted from the segmentation image as an analysis region where the whole aperture part exists. At first, an exploration window, 1 voxel in $x$-direction and 360 voxels in $y$-direction is defined. Second, each voxel in the exploration window is searched in the $y$-direction. Then, the position where a voxel of the rock phase locates above a voxel of the void phase is detected as the upper aperture, whereas the position where a voxel of the rock phase locates below a voxel of the void phase is detected as the lower aperture. As shown in Fig. 7(d), the aperture width corresponds to the number of voxels for the void phase between the upper and lower apertures.

If there is no voxel for the void phase in the exploration window, this position is regarded as the fracture contact-area. The voxel search is performed for the exploration window set at each $x$-coordinate in the analysis region. In this study, the number of contact-area positions to the number of voxels in the $x$-direction of the analysis region is defined as the fracture contact-area ratio.

The same processing as mentioned above is applied to all of the segmentation images, providing the internal fracture information, i.e., aperture distribution and the fracture contact- 
(a)

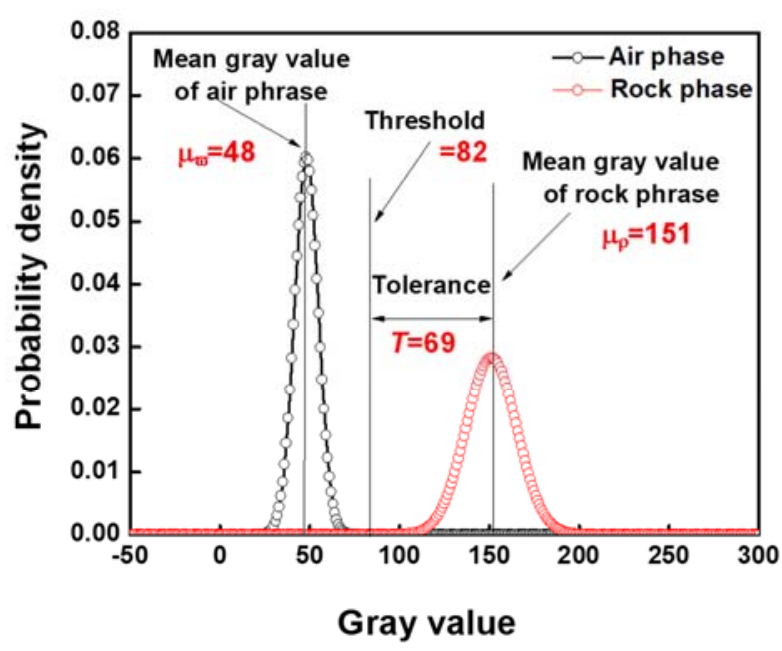

(b)

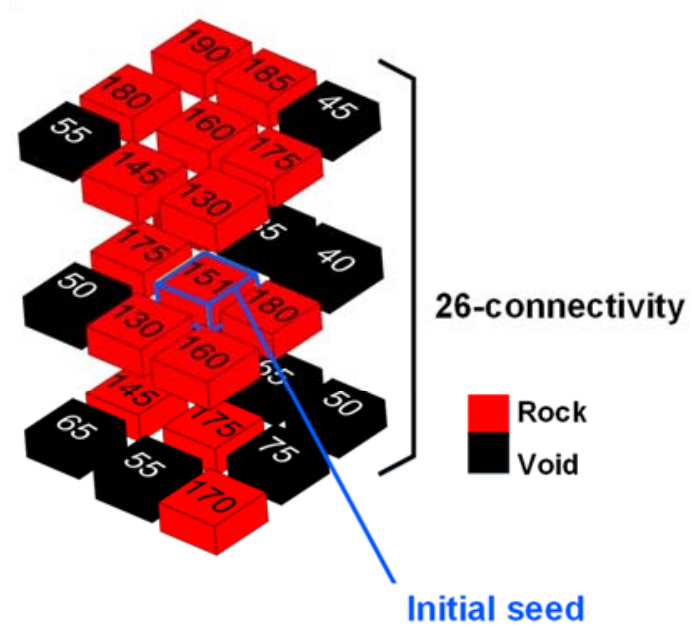

(c)

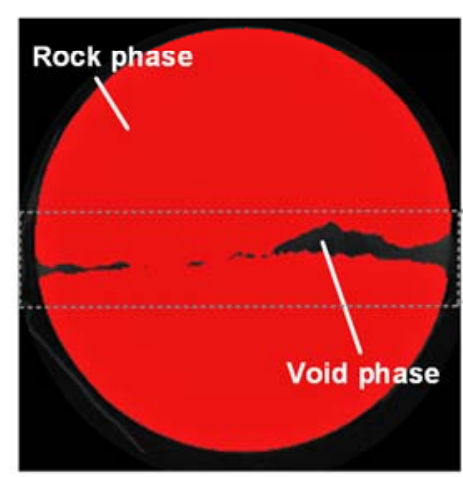

(d)

Fig. 7 Segmentation process for rock phase and void phase by region-growing technique:(a) determination of region growing, (b) schematic illustration of region growing in 3D, voxel connectivity of 26-connected neighborhood (c) segmentation image in 2 dimensional and (d) voxel that includes rock and void phases (aperture detection method) and fracture contact-area in aperture position

800 voxels

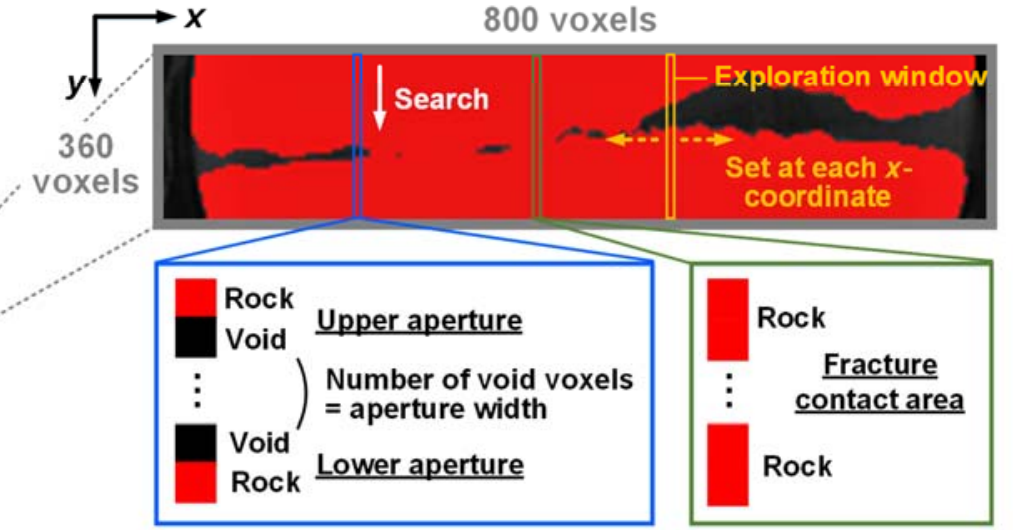
fracture contact-area in aperture position

\subsubsection{Validation of the CT image analysis}

Figures 8(a) and (b) present the contour map of the surface roughness (Sample \#2) measured by the optical profilometer (VG-3200) and that are analyzed by the CT image analysis method. For both of them the data are obtained at $0 \mathrm{MPa}$, as-received condition before starting the experiment. It is clarified that the extracted surface roughness of Sample \#2 under the two methods is qualitatively similar to each other. Figure 8(c) shows the contour map of the aperture distribution measured by the CT image analysis. This distribution is derived from the aperture 
width for each CT slice, i.e., the difference between the upper aperture and the lower aperture, as mentioned in Subsection 2.5.2. The blue part of the contour map in Fig. 8(c) represents the fracture contact-area. The initial arithmetical mean aperture (hereinafter called the mechanical aperture) and the fracture contact-area ratio without the confining pressure are $0.253 \mathrm{~mm}$ and $5.4 \%$, respectively.

(a)

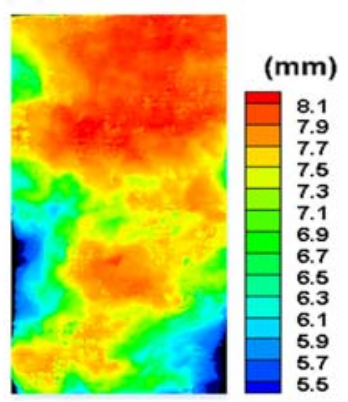

Surface roughness

(VG-3200) (b)

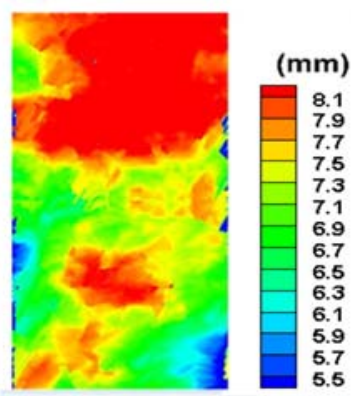

Surface roughness

(CT image analysis) (c)

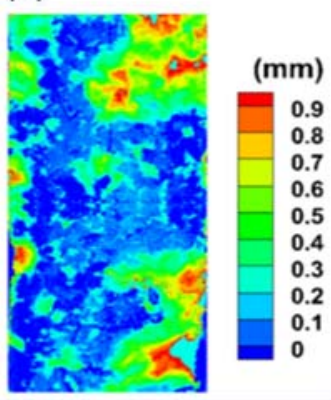

Aperture distribution

(CT image analysis)

Fig.8 Contour maps of surface roughness (A-Side as mentioned in Fig.1) and aperture distribution of Sample \#2 at 0 MPa. (a) surface roughness obtained through VG-3200 pattern projection, (b) surface roughness measured through the CT image analysis, and (c) aperture distribution measured through the CT image analysis.

\section{Experimental results}

\subsection{Short-term permeability tests}

Figure 9 illustrates the changes in permeability with different levels of confining pressure and temperature. In the figure, the right-pointing and left-pointing triangles represent the loading and unloading processes, respectively. At $20^{\circ} \mathrm{C}$ (Fig. 9(a)), the permeability decreases with the increase in confining pressure, and increases with the decrease in confining pressure throughout the tests. In particular, the permeability changes greatly and irreversibly in the first cycle of the loading-to-unloading process. Before the first cycle, the fractures may be ill-mated, and the matedness is improved through the first cycle. In the second and third cycles, reversible 
hysteresis curves are observed.

At 60 and $90^{\circ} \mathrm{C}$ (Figs. 9(b) and (c)), the similar changes in permeability that alter with the confining pressure, are observed. Namely, the permeability shows the reversible behavior in the loading-unloading processes. The results indicate that mechanical compaction should exert a significant influence on the permeability. The impact may be greater than the influence of the prescribed temperature. However, the measured permeability also shows a clear temperaturedependence; it decreases with the increase in temperature as shown in Fig. 9(d). In this figure, the third cycle of the permeability variation at each temperature is selected for the comparison. At $90^{\circ} \mathrm{C}$, the permeability decreases from the order of $10^{-12}$ to that of $10^{-14} \mathrm{~m}^{2}$, which is much smaller than that at 20 and $60{ }^{\circ} \mathrm{C}$. It is inferred that thermal expansion results in the aperture decrease and the fracture contact-area increase. Moreover, other potential factors, such as the pressure solution or geochemical responses, might function against the mechanical deformation and induce irreversible permeability behavior (Polak et al., 2003,2004; Yasuhara et al., 2006,2015). 


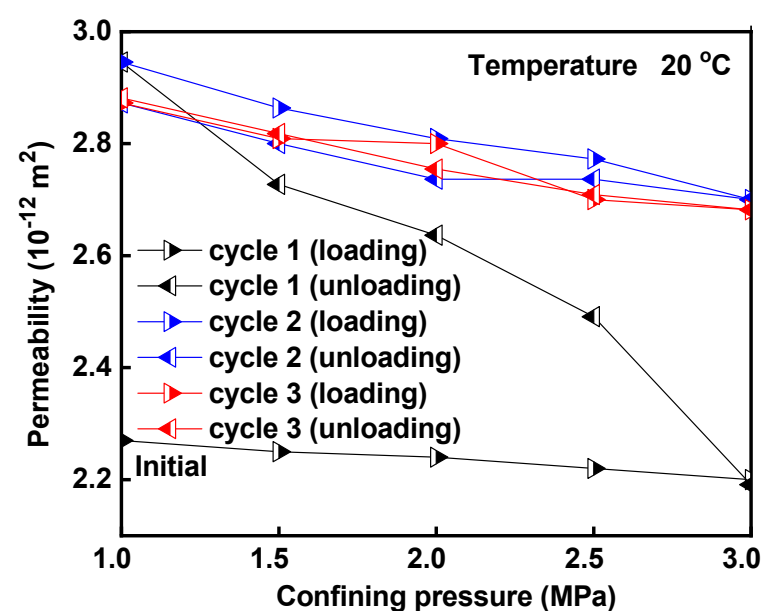

(a)

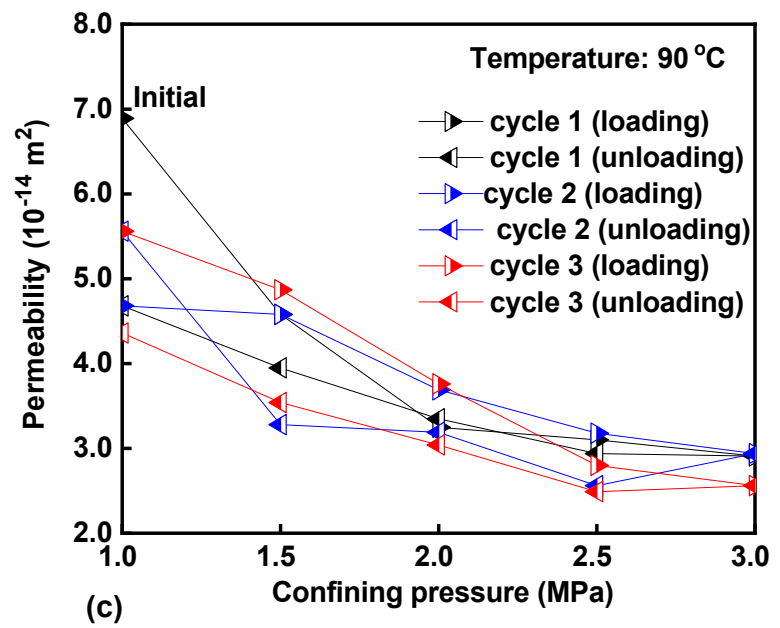

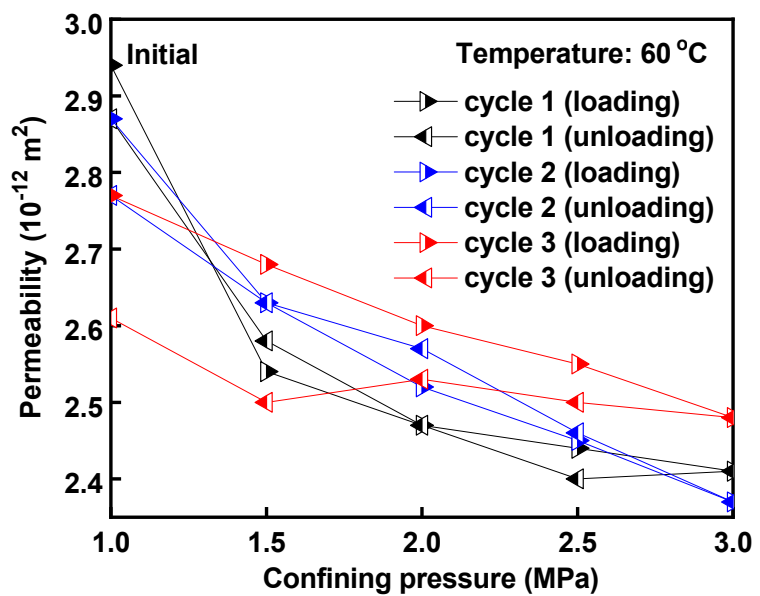

(b)

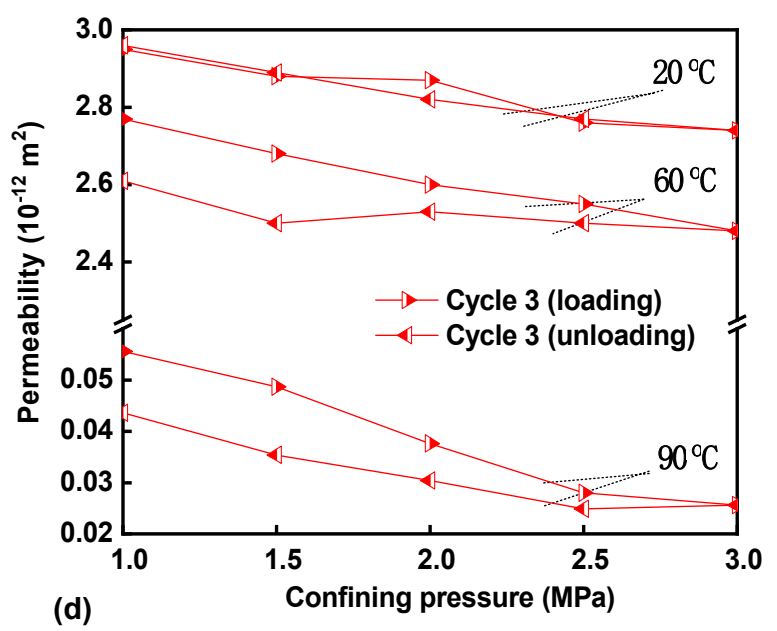

(d)

Fig. 9 Short-term test results: (a) permeability variation at $20^{\circ} \mathrm{C}$, (b) permeability variation at $60{ }^{\circ} \mathrm{C}$, (c) permeability variation at $90^{\circ} \mathrm{C}$ and (d) permeability variation in third cycle under different temperature conditions

\subsection{Long-term permeability tests}

Before the commencement of the long-term tests, the permeability increases from 4.36 $\times 10^{-14} \mathrm{~m}^{2}$ to $4.18 \times 10^{-13} \mathrm{~m}^{2}$ after the temperature is decreased from 90 to $20{ }^{\circ} \mathrm{C}$ at $1.0 \mathrm{MPa}$. This change is attributed to the increase in pore volume due to the decrease in temperature.

Figure 10 shows the temporal change in the permeability measured in the long-term tests under the constant confining pressure of 3.0 MPa. The initial permeability is $3.7 \times 10^{-13} \mathrm{~m}^{2}$. The permeability drops sharply within several days and decreases about $45 \%$ of the initial value. This change can be interpreted as the mechanical compaction changing the permeability. 
348 Subsequently, permeability resumes its decrease after a short stable period. The permeability 349 decreases to $87 \%$ of the initial value between 30 and 120 days. Creep deformation might lead 350 to a reduction in permeability when the fluid passes through a stressed fracture. From 120 to 180 days, the permeability shows a slight increase. At the end of the 180-day test, the permeability value reaches to $7 \times 10^{-14} \mathrm{~m}^{2}$.

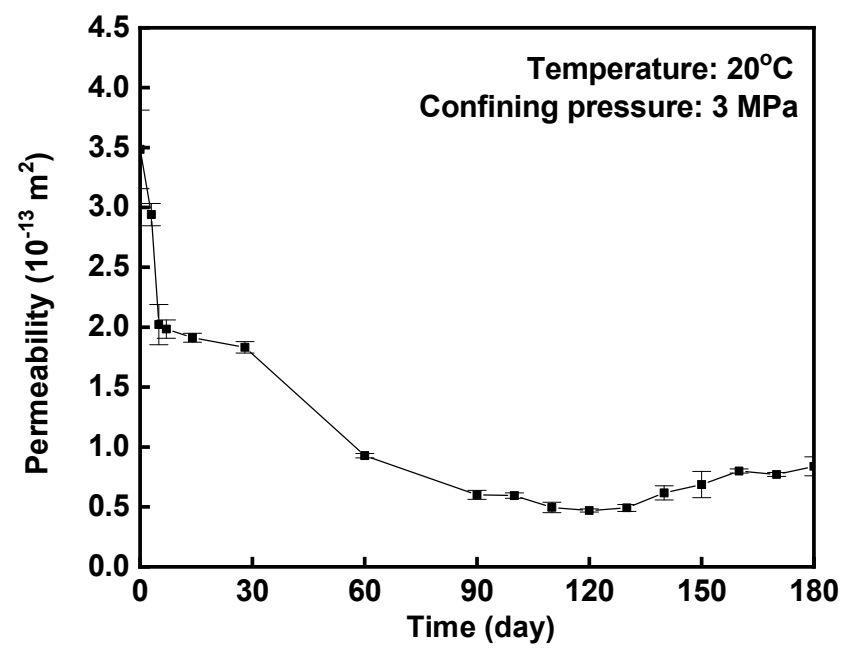

Fig. 10 Change in permeability with time (Sample \#1) at $20^{\circ} \mathrm{C}, 180$ days

At the end of the long-term permeability tests, the confining pressure has been unloaded to $1.0 \mathrm{MPa}$. The permeability evolution during the long-term cycle of the loading-to-unloading process after the 180-day holding is shown in Fig. 11(a). Although the permeability within the unloading process shows a little change, an irreversible reduction in permeability is observed between the onset and the end of the test. This trend is incongruous with the observation made by Yasuhara et al. (2013) (Fig. 11(b)), in which the long-term permeability test was conducted under a constant confining pressure of $10.0 \mathrm{MPa}$, at $20^{\circ} \mathrm{C}$ for 35 days. 


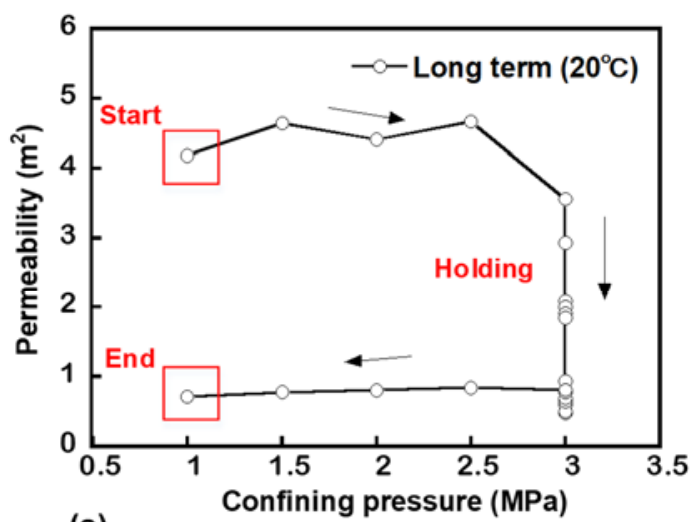

(a)

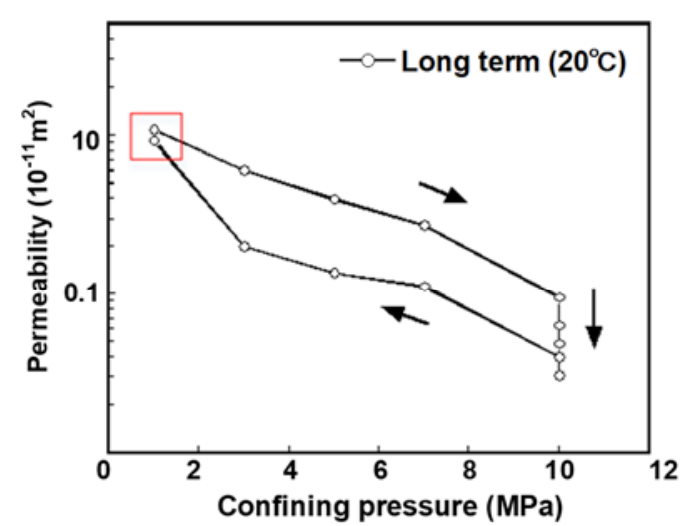

(b)

Fig. 11 Comparison of changes in permeability between (a) current work and (b) Yasuhara et al. (2013)

The irreversible permeability change is supposed that the propping asperities of the

365 fracture surfaces are truncated under a relatively long confining condition probably induced by

mechanical crushing and/or geochemical reactions such as pressure solution (Yasuhara et al., term confining condition, and it may evolve the fracture topography with time.

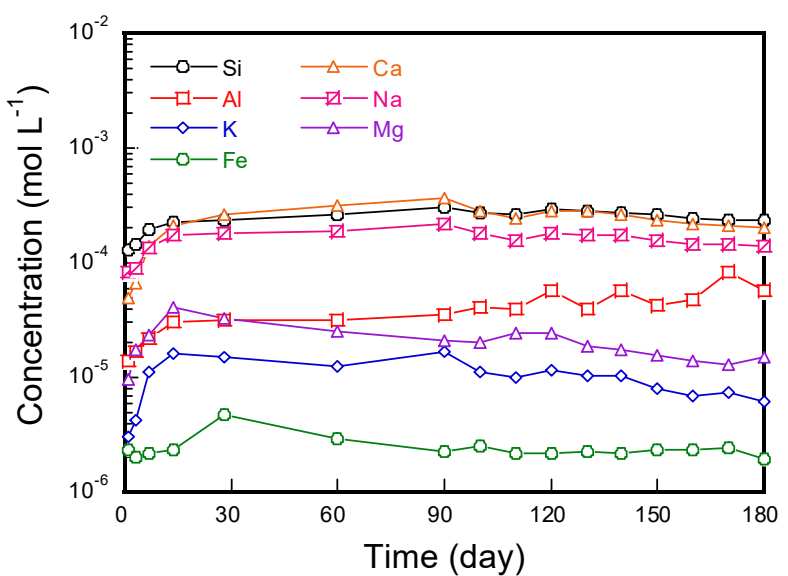




\subsection{Observation results using microfocus X-ray CT}

\subsubsection{Variation in aperture distribution}

The irreversible permeability reduction observed in the long-term tests indicates that the fracture aperture distribution will be permanently changed with time. As the important parameters for characterizing the flow paths within the fracture, the geometries of the fracture surfaces and fracture contact-area are investigated by the X-ray CT technique.

Figure 13 shows the temporal change in the aperture distribution evaluated by the CT image analysis. In Figs.13 (a) and (b), it is clearly seen from the contour maps that the bluecolored area (i.e., fracture contact-area) increases with the increase of the confining pressure. When closely observing Figs. 13 (b) to (d), the blue-colored area seems monotonically increasing with time. Namely, the fracture contact-area is enlarged. In Fig.13 (e), the aperture decrease with time can be clearly observed from the CT images, and it is corresponding to the image analysis results.

Therefore, the fracture contact-area increase can be explained by two processes. In the first process, the fracture aperture is drastically decreased due to the mechanical compaction by the increased confining pressure, which is similar to the permeability behavior observed in the short-term tests. In the second process, the creep deformation induces the long-term alteration of the fracture roughness surface under the constant confining pressure. Obviously, the second process also results in the long-term evolution of the fracture permeability. 


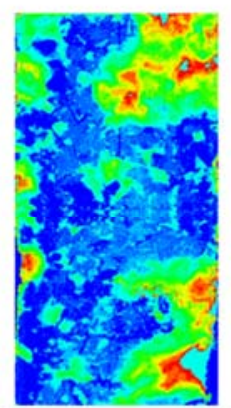

(a) $0 \mathrm{MPa}$ (0th day)

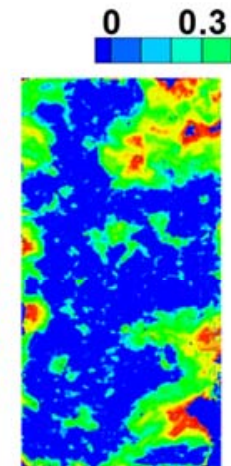

(b) $3 \mathrm{MPa}$ (0th day)

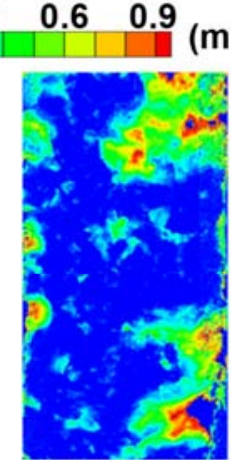

(c) $3 \mathrm{MPa}$ (90th day)

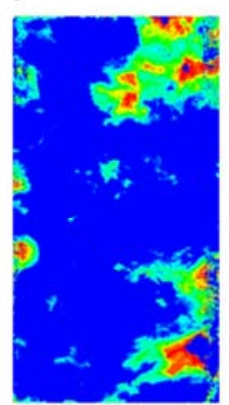

(d) $3 \mathrm{MPa}$ (180th day)

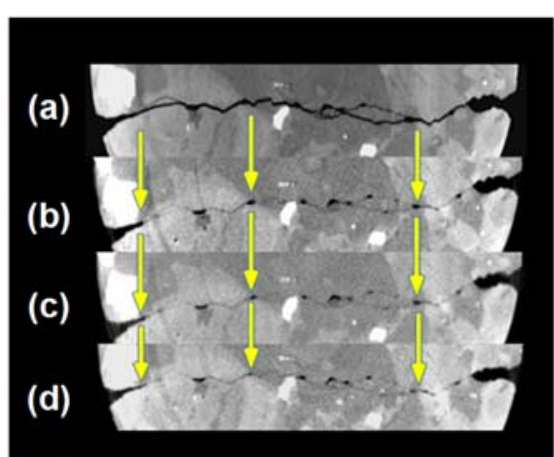

(e) Cross-section CT image comparison
398

399

400

401

402

403

404

Fig. 13 Temporal changes in aperture variation evaluated from CT analysis in long-term tests: (a) initial value of mean aperture at $0 \mathrm{MPa}$, (b) aperture variation after 0 days at $3.0 \mathrm{MPa}$, (c) after 90 days; (d) after 180 days and (e) cross-section CT images comparison from (a) to (d)

\subsubsection{Quantification of mechanical aperture and fracture contact-area ratio}

Figure 14(a) and (b) present temporal changes in the mean values of the mechanical aperture and the fracture contact-area ratio calculated by the image analysis, respectively. The aperture value drastically decreases from $0 \mathrm{MPa}$ to $3.0 \mathrm{MPa}$ and the contact-area ratio increases from $5 \%$ to $33 \%$. At a constant confining pressure of $3.0 \mathrm{MPa}$, the mechanical aperture decreases gradually to $7.5 \%$ from 0 to 90 days. Then, it further decreases to $10 \%$ from 90 to 180 days.

Simultaneously, the tendency for the fracture contact-area ratio increasing is confirmed. The contact-area ratio reaches approximately $37 \%$ at 180 days.

Previous studies used numerical methods to evaluate the fracture contact-area ratio. Yasuhara et al. (2004) predicted the fracture contact-area ratio less than $30 \%$ at $2.73 \mathrm{MPa}$ and higher temperatures ranging from 80 to $150{ }^{\circ} \mathrm{C}$. In contrast, the contact-ratio value evaluated in this study is larger than $30 \%$ at $3.0 \mathrm{MPa}$ - the calculated value tends to be relatively overestimated compared to those predicted values in the previous studies. The possible reasons for the discrepancy may be due to the accuracy of the image analysis method as introduced in section 2.5.2, the spatial resolution of CT images, and so on. It is certain, however, that no 
previous laboratory study other than the current study has verified the long-term change in the actual contact ratio value with/without confining pressure. Moreover, the tendency for the contact-area ratio increase calculated by the image analysis is in good agreement with the observation of the fracture contact-area ratio is one of the variable findings in this study, which contact-area increasing under the constant confining pressure.

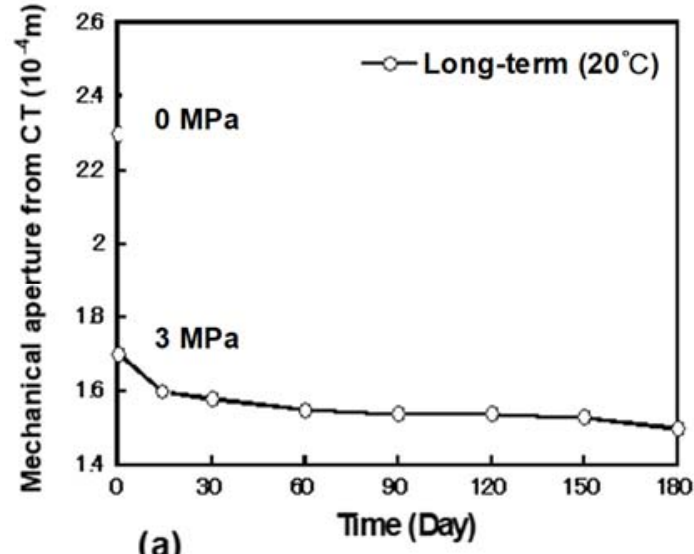

(a)

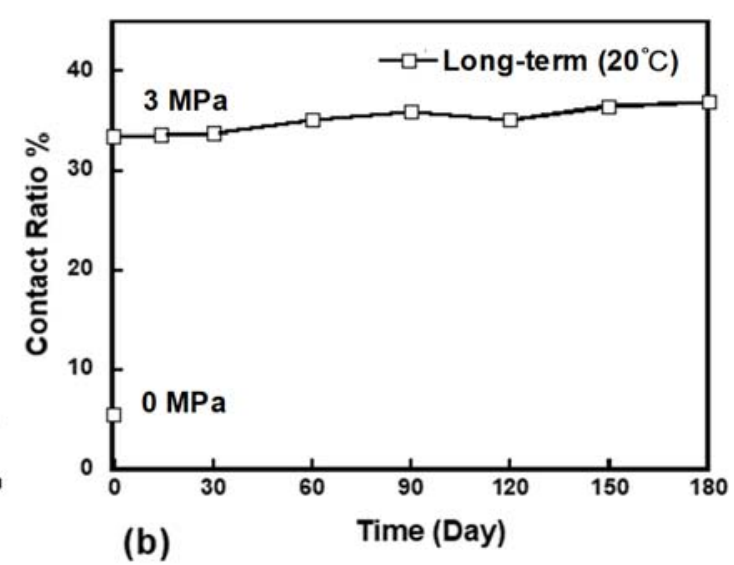

(b)

Fig. 14 Temporal changes in (a) mean aperture value and (b) contact-area ratio variation from CT image analysis

\section{Discussions}

\subsection{Short- and long-term permeability tests}

Figure 15 shows a summary of the permeability tests, in which red points represent the permeability values at 1.0 MPa, and blue points are the values at 3.0 MPa. It is clearly seen that permeability is sensitive to the confining pressures in the short-term. The permeability value at 1.0 $\mathrm{MPa}$ is larger than that at $3.0 \mathrm{MPa}$. Then the temperature was then reduced to $20{ }^{\circ} \mathrm{C}$ again after the short-term tests. The permeability value seems increase, however, it cannot reach the initial value of the short-term test at $20^{\circ} \mathrm{C}$. Moreover, the permeability is not sensitive to the 
confining pressure when reloading the confining pressure again.

At the long-term tests, the permeability decreases remarkably in the early period, which is probably resulted from the mechanical compaction due to an increment of confining pressure (see CT images Figs. 13(a) and (b)). Permeability value after the long-term test is slightly higher than the value at the short-term $90{ }^{\circ} \mathrm{C}$. It indicates that the internal fracture aperture is deformed with time in the long-term. The irreversible crushing and/or dissolution at the contacting asperities, rather than elastic and reversible compaction, might be a reason for the phenomena in the long-term tests (Yasuhara, et al., 2015).
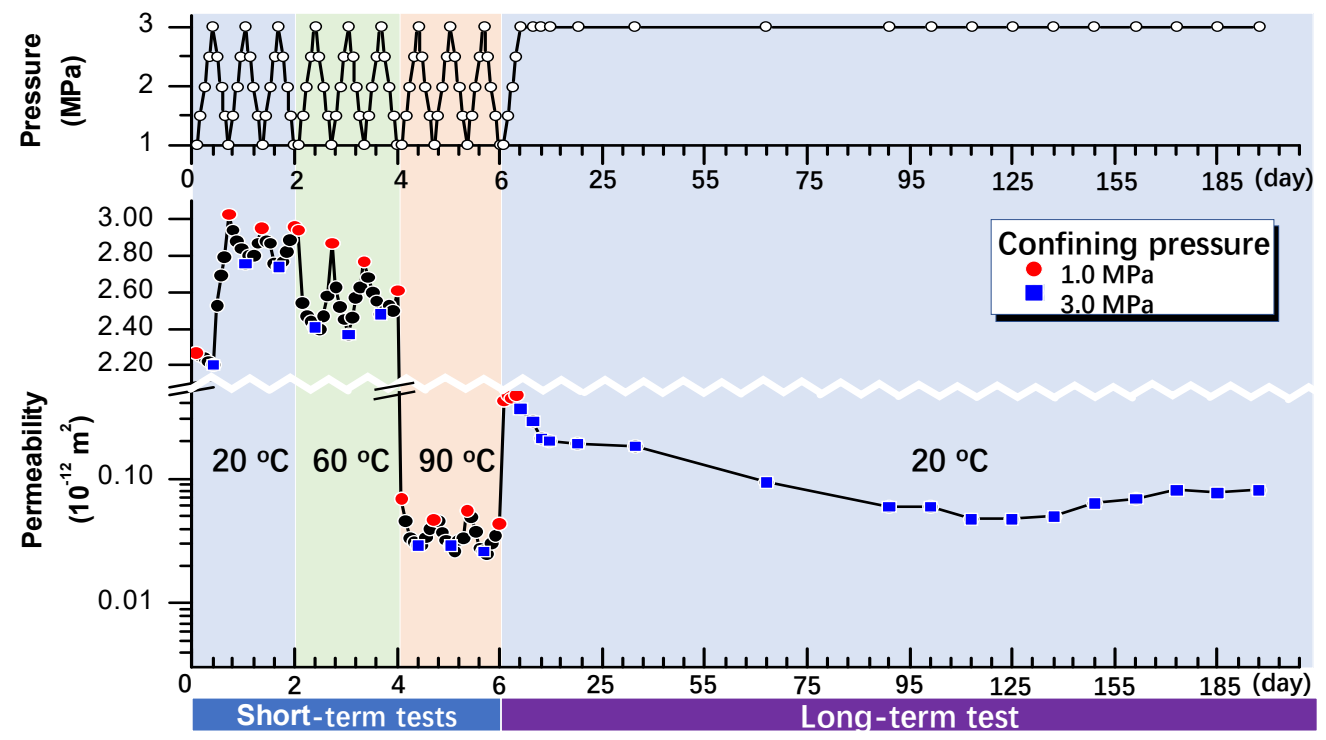

Fig. 15 Summary of permeability changes in short- and long-term tests

\subsection{Relation between hydraulic aperture and mechanical aperture}

Figure 16(a) shows a comparison of the mechanical aperture measured by the CT observation and the hydraulic aperture which is calculated from the mechanical aperture. The mechanical aperture shows a relationship between the hydraulic aperture and the fracture contact-area ratio, as defined by, Farough et al. (2016).

$$
\mathrm{b}_{\mathrm{H}}^{3}=\mathrm{b}_{\mathrm{M}}^{3}\left(1-\mathrm{R}_{C}\right) /\left(1+\mathrm{R}_{C}\right)
$$

where $b_{H}$ is the hydraulic aperture, $b_{M}$ is mechanical aperture measured from CT observation, 
and $\mathrm{R}_{\mathrm{C}}$ is the fracture contact-area ratio calculated from CT image analysis. It is noted from Fig. 16(a) that hydraulic aperture is lower than the mechanical aperture, which is congruent with the previous studies that the real roughness characteristics influence the fluid passing through the aperture, and result in the hydraulic aperture lower than the mechanical aperture (Bandis et al., 1985; Renshaw,1995; Zimmerman et al.,2004; Liu, 2005;Kishida et al., 2013).

\subsection{Relation between permeability and internal fracture structure}

To investigate the correlation between variations in the permeability and the fracture aperture, the relation between hydraulic aperture measured from the permeability tests and that calculated from the X-ray CT observation of the mechanical aperture is discussed. Figure 16(b) shows a comparison of the hydraulic apertures. The hydraulic aperture obtained from the permeability test is always lower than that obtained from the X-ray CT. From the initial hydraulic aperture value to the end value after 180 days, the decreasing gradient of the hydraulic aperture obtained from the permeability tests is about $52 \%$ and the decreasing gradient from the $\mathrm{CT}$ is about $12 \%$.

The difference in the decreasing gradient mentioned above will be summarized for two reasons. Firstly, the granite Sample \#1 experiences various levels of temperature and confining pressure in the short-term tests before the long-term tests, whereas the granite Sample \#2 is used only for the long-term permeability tests. The fracture roughness surfaces of Sample \#1 are deformed during the short-term tests under the coupled conditions. This deformation results in the evolution of the aperture and the decrease of the initial aperture value. Secondly, the two samples are different in size, which should also generate the initial aperture difference.

However, from Fig.16(b), it is noted that the hydraulic aperture evolutions obtained by the 
permeability tests and X-ray CT are quite similar. Both of them show that the hydraulic aperture decreases with time. From this comparison, the reason for the permeability decreasing in the long-term can be explained by the temporal change in the fracture aperture.

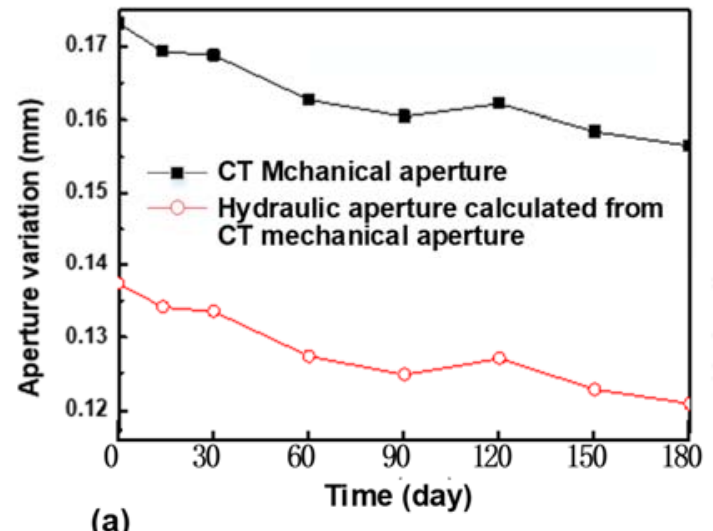

(a)

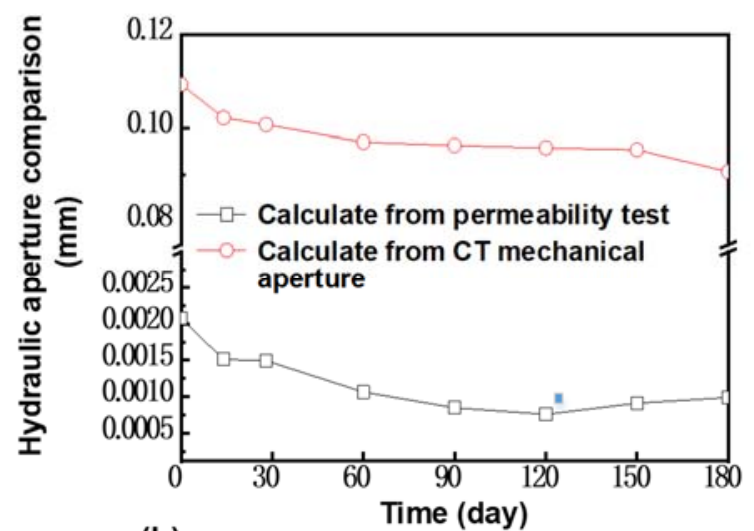

(b)

Fig. 16 (a) Comparison result of CT mechanical aperture and hydraulic aperture. (b) Comparison of changes in hydraulic aperture calculated from permeability tests and from CT observation of mechanical apertures

\section{Conclusions}

This study carried out a series of short- and long-term permeability tests under various conditions. To clarify the long-term permeability evolution, variations in the fracture aperture and fracture contact-area were investigated using a microfocus X-ray CT and image analysis technique. The relation between the hydraulic aperture obtained from the permeability tests and that estimated from the X-ray CT observation was evaluated. The influence of the internal fracture structure variation on the permeability was discussed. The conclusions are drawn as follows:

1) In the short-term permeability tests, permeability is sensitive to the confining pressures and temperatures and shows a clear temperature-dependence - it drastically decreases when applying a high temperature of $90{ }^{\circ} \mathrm{C}$. The internal fracture may be reversibly deformed, and permeability is not sensitive to the confining pressure when reloading the confining 
pressure again before starting the long-term tests. In the long-term tests, permeability evolution showed that the internal fracture structure was irreversibly deformed under a long-term compaction condition. This deformation will change permeability behavior.

2) Triaxial apparatus coupled with the microfocus X-ray CT equipment was developed in this study, to observe the long-term fracture structure change under various levels of confining pressures and temperatures. Results show that the fracture aperture decreases with increase of the confining pressure from $0 \mathrm{MPa}$ to $3 \mathrm{MPa}$, and it gradually decreases with time at the

3) The morphology of the fracture surface roughness was successfully obtained by the CT image analysis, which showed quite similar to that was obtained by the optical profilometer. The fracture contact-area ratios calculated by the image analysis are relatively larger than those shown in the literature. However, this study successfully obtains the contact-area ratio through the experimental approach and captures the long-term evolution of an actual rock

4) The hydraulic aperture value measured from the long-term permeability tests is lower than that estimated from the X-ray CT. This mismatch is probably attributed to the difference of the sample size. Moreover, before the long-term permeability tests, Sample \#1 experienced short-term permeability tests, and the aperture distribution has been altered under the coupled conditions, while Sample \#2 was not used to conduct any pre-tests. Those reasons may lead to the difference in the hydraulic aperture values.

5) The decreasing gradient of the hydraulic aperture measured from the permeability tests is qualitatively similar to that estimated from the CT observation. Therefore, the fracture 

decrease in the long-term.

\section{Acknowledgments}

This work was supported by the KAJIMA Foundation, Japan and by the Ministry of

Education, Culture, Sports, Science and Technology (MEXT) scholarship (Project Code No.

\section{References}

530 1. Frdric, B., Frank, L., Pierre, D.C., Valr, D., 2017. Implications of safety requirements for the treatment of THMC processes in geological disposal systems for radioactive waste. Journal of Rock Mechanics and Geotechnical Engineering.9(3):428-434. Berniera, F., Lemy, F., De Cannièrea, P., Detilleuxb, V., 2017. Implications of safety requirements for the treatment of THMC processes in geological disposal systems for radioactive waste. Journal of Rock Mechanics and Geotechnical Engineering. 9(3):428-434.

2. Ghassemi,_A., Kumar, G.S., 2007. Changes in fracture aperture and fluid pressure due to thermal stress and silica dissolution/precipitation induced by heat extraction from subsurface rocks. Geothermics.36:115-140.

3. Taron, J., Elsworth, D., 2010. Coupled mechanical and chemical processes in engineered geothermal reservoirs with dynamic permeability. International Journal of Rock Mechanics and Mining Sciences.47(8):1339-1348. high-level radioactive waste repository in clay formations. International Journal of Rock Mechanics and Mining 
and deformation in fractured porous rock. International Journal of Rock Mechanics and Mining Sciences.39:429-442.

6. Yasuhara, H., Kinoshita, N., Ohfuji, H., Kishida, K., 2015. Long-term observation of permeability in sedimentary rocks under high-temperature and stress conditions and its interpretation mediated by microstructural investigations. Water Resources Research.51(7):5425-5449.

7. Xu, P., Yang, S.Q., 2016. Permeability evolution of sandstone under short-term and long-term triaxial compression. International Journal of Rock Mechanics and Mining Sciences.85:152-164.

8. Yasuhara, H., Polak, A., Elsworth, D., 2006. Evolution of fracture permeability through fluid-rock reaction under hydrothermal conditions. Erath Planetary Science Letters.244:186-200.

9. Yasuhara, H, Elsworth, D., 2004. Evolution permeability in a natural fracture: significant role of pressure solution. Journal of Geophysical Research.109(B03204):1029-1038.doi:10.1029/2003JB002663.

10. Yasuhara, H., Kinoshita, H., Kishida, K., 2011. Temporal alteration of fracture permeability in granite under hydrothermal conditions and its interpretation by coupled chemo-mechanical model. Applied Geochemistry.26:2074-2088.

11. Polak, A., Elsworth, D., Liu, J., 2004. Spontaneous switching of permeability changes in a limestone fracture with net dissolution. Water Resource. Research.40(W03502).

12. Beeler, N.M., Hickman, S.H., 2004. Stress-induced, time-dependent fracture closure at hydrothermal conditions. Journal of Geophysical Research: Solid Earth.109(B02211).

13. Elkhoury, J.E., Detwiler, R.L., Ameli, P., 2013. Dissolution and deformation in fractured carbonates caused by flow of CO2-rich brine under reservoir conditions. International Journal of Greenhouse Gas Control.16:203-215.

14. Wang, Y., 2017. On subsurface fracture opening and closure. Journal of Petroleum Science and Engineering.155:46-53. a ventilated tunnel in an argillaceous rock. Journal of Rock Mechanics and Geotechnical Engineering.5(2):145-155. 
Mechanics and Mining Sciences.45(3):362-375.

17. Polak, A,. Elsworth, D., Yasuhara, H., 2003. Permeability reduction of a natural fracture under net dissolution by hydrothermal fluids. Geophysical Research Letters.30(20).

18. Farough, A., Moore, D.E., Lockner, D.A., Lowell, R.P., 2016. Evolution of fracture permeability of ultramafic rocks undergoing serpentinization at hydrothermal conditions: An experimental study. Geochemistry, Geophysics, Geosystems.17(1):44-55.

19. Zimmerman, R.W., Bodvarsson, G.S., 1996. Hydraulic conductivity of rock fractures. Transport in Porous Media.23:130.

20. Kishida, K., Sawada, A., Yasuhara, H., 2013. Estimation of fracture flow considering the inhomogeneous structure of single rock fractures. Soils and Foundations.53(1):105-116.

21. Ketcham, R.A., Slottke, D.T., Sharp, J.M., 2010. Three-dimensional measurement of fractures in heterogeneous materials using high-resolution X-ray computed tomography. Geosphere.6:499-514.

22. Van, G. M., Swennen, R., David, P., 2001. Quantitative coal characterisation by means of microfocus X-ray computer tomography, colour image analysis and back-scattered scanning electron microscopy. International Journal of Coal Geology.46:11-25.

23. Yao, Y., Liu, D., Che, Y., 2009. Non-destructive characterization of coal samples from China using microfocus X-ray computed tomography. International Journal of Coal Geology.80:113-23.

24. Fan, H.Z., Jian, C.G., Shou, M., 2018. 3D observations of the hydraulic fracturing process for a model noncemented horizontal well under true triaxial conditions using an X-ray CT imaging technique. Journal of Natural Gas Science and Engineering. 52:128-140. 
26. Dustin, C., Johnathan, M.B., Magdalena, G.B., 2017. CT scanning and flow measurements of shale fractures after multiple shearing events. International Journal of Rock Mechanics and Mining Sciences.100:177-187.

27. Lu, X., Ryan, T., Armstrong., 2018. High-pressure X-ray imaging to interpret coal permeability.Fuel.226:573-582.

28. Kumaria, W.G.P., Ranjith, P.G., Pererab, M.S.A., Li, X., 2018. Hydraulic fracturing under high temperature and pressure conditions with micro CT applications: Geothermal energy from hot dry rocks.Fuel.230:138-154.

29. Karpyn, Z.T., Alajmi, B.A., Radaelli, C.F., 2009. X-ray CT and hydraulic evidence for a relationship between fracture conductivity and adjacent matrix porosity. Engineering Geology.103:139-145.

30. Stephanie, P., Bertels., David, A., 2001. Measurement of aperture distribution, capillary pressure relative permeability, and in situ saturation in a rock fracture using computed tomography scanning. Water Resource Research.37(3):649-662.

31. Karpyn, Z.T., Grader, A.S., Halleck, P.M., 2007. Visualization of fluid occupancy in a rough fracture using microtomography. Journal of Colloid and Interface Science.307:181-187.

32. Mazumder, S., Wolf, K., Elewaut, K., Ephraim, R., 2006. Application of X-ray computed tomography for analyzing cleat spacing and cleat aperture in coal samples. International Journal of Coal Geology.68:205-22.

33. Keller, A., 1998. High resolution, non-destructive measurement and characterization of fracture apertures. International Journal of Rock Mechanics and Mining Sciences.35:1037-1050.

34. Hamed, L.R., Ryan, T., Armstrong, P.M., 2016. Micro-CT image calibration to improve fracture aperture measurement. Case Studies in Nondestructive Testing and Evaluation.6:4-13.

35. Yao, Y.B., Liu, D.M., Che, Y., 2009. Non-destructive characterization of coal samples from China using microfocus Xray computed tomography. International Journal of Coal Geology.80:113-123. high-resolution X-ray computed tomography.Geosphere.6(5):499-514. 
under uniaxial and triaxial conditions by X-ray CT scan. Tectonophysics.313:293-305.

38. Okamoto, A., Tanaka, H., Watanabe, N., Saishu, H., Tsuchiya, N., 2017. Fluid Pocket Generation in Response to Heterogeneous Reactivity of a Rock Fracture Under Hydrothermal Conditions. Geophysical Research Letters.44(20):10306-10315.

39. Kamali-Asl, A., Kc, B., Foroutan, M., Ghazanfari, E., Cladouhos, T., 2018. Experimental study of fracture response in granite specimens subjected to hydrothermal conditions relevant for enhanced geothermal systems.Geothermics.72:205224.

40. Caulk, R.A., Ghazanfari, E., Perdrial, J.N., Perdrial, N., 2016. Experimental investigation of fracture aperture and permeability change within Enhanced Geothermal Systems. Geothermics.62:12-21.

41. Fairhurst, C., 1964. On the validity of the 'Brazilian' test for brittle materials. International Journal of Rock Mechanics and Mining Sciences.1(4):535-546.

42. Barton, N., Quadros, D.E.F., 1997. Joint aperture and roughness in the prediction of flow and groutability of rock masses. International Journal of Rock Mechanics and Mining Sciences.34:3-4.

43. Barton, N., Choubey, V., 1977. The Shear Strength of Rock Joints in Theory and Practice. Rock Mechanics. 10: 1-65. 1977.

44. Tse, R., Cruden, D.M., 1979. Estimating joint roughness coefficients, International Journal of Rock Mechanics and Mining Sciences.16:303-307.

45. Zhang, G.C., Karaku, S.M., Tang, H.M., 2014. A new method estimating the 2D Joint Roughness Coefficient for discontinuity surfaces in rock masses. International Journal of Rock Mechanics and Mining Sciences.72:191-198.

46. Dimadis, G., Dimadi, A., Bacasis, I., 2014. Influence of fracture roughness on aperture fracture surface and in fluid flow on oarse-grained marble, experimental results. Journal of Geoscience and Environment Protection.2:59-67.

47. Yong, R., Ye, J., Liang, Q.F., 2018. Estimation of the joint roughness coefficient (JRC) of rock joints by vector similarity measures. Bull Eng Geol Environment. 
48. Yin, Q., Ma,G.W., Jing, H.W., 2017. Hydraulic properties of 3D rough-walled fractures during shearing: An experimental study. Journal of Hydrology.555:169-184.

49. Hsieh, P. A., Tracy, J.V., Neuzil, C.E., 1981. A transient laboratory method for determining the hydraulic properties of 'tight' rocks-I. Theory. International Journal of Rock Mechanics and Mining Sciences \& Geomechanics Abstracts.18:245-252.

50. Otani, J., Mukunoki, T., and Obara, Y. 2002. Characterization of failure in sand under triaxial compression using industrial X-ray CT scanner. International journal of physical modeling in geotechnics.2:15-22.

51. Kido, R., Higo,Y., Takamura, F., Morishita, R., Khaddour, G., 2020. Simon Salager Morphological transitions for pore water and pore air during drying and wetting processes in partially saturated sand, Acta Geotechnica.

53. Higo, Y., Oka, F., Morishita, R., ,Matsushima, Y., Yoshida, T., 2014. Trinarization of $\mu$ X-ray CT images of partially saturated sand at different water-retention states using a region growing method. Nuclear Instruments and Methods in Physics Research Section B: Beam Interactions with Materials and Atoms.324:63-69.

54. Otsu, N., 1979. A Threshold Selection Method from Gray-Level Histogram. IEEE Trans. Systems Man, and Cybernetics.9:62-66.

55. Yasuhara, H., Hasegawa, D., Nakashima, S., Kishida, K., 2013. Experimental evaluation of fracture permeability in granite under temperature and stress controlled conditions. Japanese Geotechnical-Journal.8:71-79.

56. Walsh, J.B., 1981. The Effect of Pore Pressure and Confining Pressure on Fracture Permeability. International Journal of Rock Mechanics and Mining Sciences.18:429-435. Symposium. Fundamentals of Rock Joints, Bjørkliden.269-280. 

seismic characterization of fractured reservoirs. Journal of Geophysics and Engineering.2(1):38-47.

658 60. Zimmerman, R.W., Main, I.G., 2004. Chapter7-Hydromechanical behaviour of fractured rocks. International 